\title{
Unplanned hospitalizations in patients
} with locoregionally advanced head and neck cancer treated with (chemo)radiotherapy with and without prophylactic percutaneous endoscopic gastrostomy

Beat Bojaxhiu ${ }^{1,2,5}$, Binaya K. Shrestha ${ }^{1 \dagger}$, Pascal Luterbacher ${ }^{1 \dagger}$, Olgun Elicin ${ }^{1}$, Mohamed Shelan ${ }^{1}$, Andrew J. S. Macpherson ${ }^{3}$, Benjamin Heimgartner ${ }^{3}$, Roland Giger ${ }^{4}$, Daniel M. Aebersold ${ }^{1}$ and Kathrin Zaugg ${ }^{1,5^{*}}$

\begin{abstract}
Background: Current studies about percutaneous endoscopic gastrostomy (PEG) tube placement report equivalent patient outcomes with prophylactic PEG tubes (pPEGs) versus common nutritional support. Unreported was if omitting a pPEG is associated with an increased risk of complications leading to a treatment-related unplanned hospitalization (TRUH).

Methods: TRUHs were retrospectively analyzed in patients with advanced head and neck squamous cell carcinoma $(n=310)$ undergoing (chemo)radiotherapy with (pPEG) or without PEG (nPEG).

Results: In 88 patients (28\%), TRUH was reported. One of the leading causes of TRUH in nPEG patients was inadequate oral intake $(n=16,13 \%)$, and in PPEG patients, complications after PEG tube insertion $(n=12,10 \%)$. Risk factors for TRUH were poor performance status, tobacco use, and surgical procedures.

Conclusions: Omitting PPEG tube placement without increasing the risk of an unplanned hospitalization due to dysphagia, dehydration or malnutrition, is an option in patients being carefully monitored. Patients aged $>60$ years with hypopharyngeal carcinoma, tobacco consumption, and poor performance status appear at risk of PEG tube-related complications leading to an unplanned hospitalization.
\end{abstract}

Keywords: Head and neck cancer, Percutaneous endoscopic gastrostomy, Morbidity, PEG, Radiotherapy

\section{Background}

Curative intended radiotherapy (RT) with or without concomitant chemotherapy of patients with locoregionally advanced (Union for International Cancer Control

*Correspondence: kathrin.zaugg@triemli.zuerich.ch

†Binaya K. Shrestha and Pascal Luterbacher have contributed equally to this work

1 Department of Radiation Oncology, Inselspital, Bern University Hospital, University of Bern, Bern, Switzerland

Full list of author information is available at the end of the article
[UICC] 7th edition: stage III-IVB) head and neck squamous cell carcinoma (HNSCC) may lead to malnutrition [1, 2], among other significant toxicities. An already existing dysphagia or odynophagia caused by the tumor can be aggravated by therapy-related inflammation, mucositis, and edema along the mucosal linings of the upper aero-digestive tract, as well as in the muscles of mastication and swallowing [3-5]. If this leads to grade 3 dysphagia according to Common Terminology Criteria for Adverse Events (CTCAE version 5.0) [6], feeding original author(s) and the source, provide a link to the Creative Commons licence, and indicate if changes were made. The images or other third party material in this article are included in the article's Creative Commons licence, unless indicated otherwise in a credit line to the material. If material is not included in the article's Creative Commons licence and your intended use is not permitted by statutory regulation or exceeds the permitted use, you will need to obtain permission directly from the copyright holder. To view a copy of this licence, visit http://creativecommons.org/licenses/by/4.0/. The Creative Commons Public Domain Dedication waiver (http://creativeco mmons.org/publicdomain/zero/1.0/) applies to the data made available in this article, unless otherwise stated in a credit line to the data. 
tube or total parenteral nutrition and/or hospitalization is indicated. Several feeding tube strategies can be used for this nutritional support (e.g. nasogastric tube, percutaneous endoscopic or percutaneous radiologic gastrostomy). Retrospective analyses examining the indication for PEG tube placement showed differing results, again making a conclusive statement challenging [7]. This is further complicated by the fact that a prophylactically inserted PEG (pPEG) is sometimes found subsequently not to be needed [8]. A comprehensive review found weak evidence concerning the pros and cons associated with pPEG placement and made a call for more prospective studies $[9,10]$. One of the first prospective studies to include enough patients published its first results in 2012 [10], with an extended follow-up in 2017 [11]. The study compared the use of pPEGs with common nutritional support and enteral tube feeding (when considered necessary) inserted after the start of treatment reactively (rPEG). It resulted in no difference in swallowing function, tube dependence, and the prevalence of clinically relevant esophageal strictures. There was no difference in weight, body mass index (BMI), or overall survival (OS) between the groups. There was neither an advantage nor a disadvantage for a $\mathrm{pPEG}$ versus $\mathrm{nPEG}$ or a rPEG. However, in this study no complications leading to a hospitalization were reported in the nPEG group. Our study aimed to analyze if omitting a PEG tube in LAHNSCC patients was associated with an increased risk of complications leading to an unplanned hospitalization (UH), compared to patients receiving a PEG tube prophylactically.

\section{Methods}

\section{Patients}

In this retrospective single-center chart review, we identified a database of 310 consecutive UICC stage III-IVB HNSCC patients (except for nasopharyngeal and sinonasal sites) treated between 2007 and 2012 with primary or adjuvant chemo-RT with a curative intent. Ethics committee approval (Ref.-Nr. KEK-BE: 289/2014) was obtained for this study and it has been conducted in full accordance with ethical principles, including the World Medical Association Declaration of Helsinki (version 2002) and the additional requirements.

\section{Treatment and follow-up}

Treatment strategies were based on institutional policies following the case-based multidisciplinary tumor board decision, as previously published [12,13]. Patients who were first diagnosed before 2010 (UICC 6th edition) were re-staged according to the 7th edition during data acquisition. During this period, there was no algorithm as to which patient should be recommended for a pPEG.
Prophylactic PEG placement was recommended to all patients based on the subjective evaluation of their general condition, expected radiation volume and side effects by the attending radiation oncologists. The cases in which a patient rejected a pPEG and the reasons of rejection were not systematically assessed. The planning and delivery of RT as well as the definitions of clinical target volume and planned target volume followed international recommendations [14-18]. The RT was administered with 2 Gy daily fractions using a volumetric modulated arc technique up to a total dose of 72 Gy for macroscopically detectable tumor, 66 Gy for postoperative positive or narrow resection margin(s), and the lymph node region(s) with pathological extracapsular extension. Elective nodal regions received 54 Gy. Sequential boosts were performed.

\section{Percutaneous endoscopic gastrostomy placement}

Percutaneous endoscopic gastrostomy placements (pPEG and rPEG) were performed according to the pull method described by Ponsky et al [19]. Antibiotic prophylaxis with Amoxicillin/Clavulanate $1.2 \mathrm{~g}$ intravenously and a Freka PEG gastral $15 \mathrm{Ch} /$ Fr EnFit (Fresenius Kabi, Switzerland) were routinely used.

\section{Definition of unplanned hospitalizations and follow-up}

All complications leading to a hospitalization from the initial histopathological diagnosis to the last follow-up were recorded. Emergency or unplanned admissions were defined as unplanned hospitalizations (UHs). However, elective hospitalizations, including those due to socially or logistically difficult circumstances (e.g. long journey, initially poor general condition, etc.), were not analyzed. If an elective hospitalization was associated with a complication and therefore an extension to the planned length of stay, the time from that complication to discharge was defined as an UH. UHs were classified as being related to comorbidities, index HNSCC and recurrences, or cancer treatment. When a UH was related to cancer treatment, it was defined as a treatment-related UH (TRUH). In order not to have more than three endpoints and to enable a sound and simple statistical methodology, we analyzed only the first two UHs and thus only the first two consecutive TRUHs in patients who had multiple UHs. In the case of externally UH, additional information was obtained from the hospital where the emergency took place.

\section{Toxicities and the course of body weight}

Toxicities and the course of body weight from the initial histopathological diagnosis to the last follow-up were recorded and graded according to CTCAE (version 5.0) [6]. The patient's weight was recorded before, during, and 
after therapy. Changes were graded by CTCAE: grade $1,5 \%-<10 \%$ from baseline, intervention not indicated; grade $2,10-\leq 20 \%$ from baseline, nutritional support indicated; grade $3 \geq 20 \%$ from baseline, tube feeding, or total parenteral nutrition indicated. Symptoms of pain, dermatitis, mucositis, dysphagia, xerostomia, and osteoradionecrosis were assessed. Acute and late toxicities were defined as post-treatment-related complications occurring during and/or within 3 months or $\geq 3$ months after commencing chemo-RT, respectively. Baseline pretreatment tumor-related morbidity using the same criteria were also assessed.

\section{Statistical analysis}

Patients were grouped as pPEG and nPEG. Patients who received rPEG were included in the nPEG group according to the intention-to-treat principle. The endpoints were defined as: first TRUH (TRUH1), second consecutive TRUH (TRUH2), and overall survival (OS). The start date of the first and second TRUH, and the date of death, were counted as the corresponding time points, respectively. Cox's proportional hazard model was used to evaluate time-to-event endpoints, calculated from the date of histopathological diagnosis of the initial HNSCC. For multivariate analyses, backwards stepwise elimination was performed by including variables yielding $p$ values $\leq 0.05$ in univariate analyses. Actuarial time to event rates were depicted by Kaplan-Meier methodology. The chi-squared test was used to compare categorical variables. All tests were two-tailed. No adjustment was done for multiple testing. Due to the lack of concrete evidence or consensus regarding pre-treatment risk factors for feeding tube requirement to calculate and assign propensity scores, no matched-pair analyses were performed. Statistical analyses were performed with JMP (version 14.2.0; SAS Institute, Cary, NC, USA).

\section{Results}

The median follow-up for the whole patient cohort was 32 months (range, 3-99 months). The median follow-up for the nPEG and pPEG group was 35 (range, 3-94 months), and 32 months (range, 3-99 months), respectively. Table 1 shows patient and disease characteristics. Compared with the nPEG group, the PPEG group had more patients aged $70-80$ years, with a poor performance status (Eastern Cooperative Oncology Group performance status [ECOG PS] 2/3), hypopharyngeal tumors, and more advanced $\mathrm{T}$ and $\mathrm{N}$ stages. The patients with PPEG received concomitant chemotherapy more frequently and had less frequent grade 2 weight loss during therapy than nPEG patients. One hundred forty-one of the 310 patients (46\%) had at least one UH: 88 (28\%) were TRUH1, 34 (11\%) comorbidity-related, and 19 (6\%) relapse-related. Sixty-four patients (21\%) had two consecutive UHs: 34 (11\%) were TRUH2, 16 (5\%) comorbidity-related, and $14(5 \%)$ relapse-related. Table 2 and Fig. 1a show an overview of UHs; Table 3 and Fig. 1b show an overview of TRUHs.

Beside chemo-RT-related side effects (dermatitis, mucositis, infection, pneumonia, and dyspnea), the leading causes of TRUH in the nPEG group was dysphagia/dehydration/malnutrition. In the pPEG group, PEG complications were one of the leading causes for TRUH, besides chemo-RT-related side effects (Table 3). The comparison of TRUH1 regardless of its cause was $80 \%$ versus $70 \%(p=0.09)$. The comparison of TRUH1 related to PEG complications or dysphagia/malnutrition/ dehydration related events between nPEG and pPEG groups is shown in Fig. 2. There was no significant difference $(p=0.56)$. The same analysis was not repeated for TRUH2 due to the small number of events $(n=2)$. According to univariate analysis, risk factors for a TRUH were: poor ECOG PS (2/3), tobacco use $>40$ pack-years (i.e. above the median), and surgical procedures ([bilateral] neck dissection, tracheostomy, and pPEG). In multivariate analysis, tobacco use $>40$ pack-years, bilateral neck dissection, and poor ECOG PS (2/3) remained as independent risk factors for TRUH.(Table 4). We investigated possible risk factors for a PEG-associated event in a subgroup analysis, which revealed that tumor localization to hypopharynx $(P=0.0183)$, active tobacco consumption $(P=0.0009)$, tobacco use $>40$ pack-years $(P=0.0001)$, poor ECOG PS $(2 / 3) \quad(P=0.0418)$, and age $>60$ years $(P=0.0352)$ were risk factors in the univariate analysis (data not shown). Overall survival at 3 years for the entire, nPEG, and pPEG group was $70 \%, 67 \%$, and $73 \%$, respectively. Overall survival was associated with age, ECOG PS 2-3, tumor localization to the oropharynx and hypopharynx, neck dissection, rPEG, and baseline BMI (Table 4 and Additional File 1).

\section{Discussion}

In a relatively large cohort of 310 patients with locoregionally advanced HNSCC compared with previously published studies [7, 9, 20-23], we retrospectively analyzed whether omitting a PEG compared to prophylactic PEG insertion is associated with an increased risk of complications leading to a TRUH. Although the institutional policy was to offer pPEG to all patients with locoregionally advanced HNSCC, physicians were less keen on insisting that patients with a possibly lower risk profile should receive a pPEG. Moreover, some patients refused the pPEG regardless of their risk profile. Therefore, pPEG placement tended to be used more frequently in patients with a higher risk profile and worse prognosis (comprising general condition, tumor size, age, hypopharyngeal 
Table 1 Patient and disease characteristics

\begin{tabular}{|c|c|c|c|c|}
\hline Characteristic & All patients $(n=310)$ & $\begin{array}{l}\text { pPEG } \\
(n=175)\end{array}$ & nPEG or rPEG $(n=135)$ & $P$ value \\
\hline \multicolumn{5}{|l|}{ Age at first diagnosis, years } \\
\hline Median (range) & $61(20-94)$ & $62(20-83)$ & $61(40-94)$ & ns \\
\hline$\leq 60, \mathrm{n}(\%)$ & $139(44)$ & $75(43)$ & $64(47)$ & ns \\
\hline$>60-\leq 70, n(\%)$ & $111(36)$ & $36(37)$ & $47(35)$ & ns \\
\hline$>70-\leq 80, n(\%)$ & $45(15)$ & $32(18)$ & $13(10)$ & .035 \\
\hline$>80, n(\%)$ & $15(5)$ & $4(2)$ & $11(8)$ & .029 \\
\hline \multicolumn{5}{|l|}{ Sex, n (\%) } \\
\hline Female & $75(24)$ & $129(74)$ & $106(79)$ & ns \\
\hline Male & $235(76)$ & $46(26)$ & $29(21)$ & ns \\
\hline \multicolumn{5}{|l|}{ ECOG performance status, n (\%) } \\
\hline 0 & $112(36)$ & $56(32)$ & $56(43)$ & ns \\
\hline 1 & $153(50)$ & $87(50)$ & $66(50)$ & ns \\
\hline $2 / 3$ & $40(14)$ & $30(18)$ & $9(7)$ & .006 \\
\hline Missing, $\mathrm{n}$ & 5 & 1 & 4 & na \\
\hline Median (range) baseline BMl, kg/m² & $24.9(16.8-38.7)$ & $24.9(16.8-38.6)$ & $24.9(17.6-36.8)$ & ns \\
\hline \multicolumn{5}{|c|}{ Body weight loss during RT, CTCAE grade, n (\%) } \\
\hline 0 & $135(47)$ & $92(55)$ & $43(36)$ & .002 \\
\hline 1 & $87(30)$ & $48(29)$ & $39(33)$ & ns \\
\hline 2 & $62(22)$ & $26(15)$ & $36(30)$ & .004 \\
\hline 3 & $2(1)$ & $1(1)$ & $1(1)$ & ns \\
\hline Missing, $n$ & 24 & 8 & 16 & na \\
\hline \multicolumn{5}{|l|}{ Smoking habits } \\
\hline Never smoker & $34(13)$ & $21(13)$ & $13(12)$ & ns \\
\hline Ex-smoker & $75(29)$ & $47(30)$ & $28(26)$ & ns \\
\hline Current smoker & $153(58)$ & $87(56)$ & $66(62)$ & ns \\
\hline Missing, $n$ & 48 & 20 & 28 & na \\
\hline \multicolumn{5}{|l|}{ Tobacco use, pack-years } \\
\hline Median (range) & $40(0-150)$ & $40(0-150)$ & $40(0-120)$ & ns \\
\hline > 40 (i.e. above median), n (\%) & $100(44)$ & $65(46)$ & $35(41)$ & ns \\
\hline Missing, $\mathrm{n}$ & 83 & 34 & 49 & ns \\
\hline \multicolumn{5}{|l|}{ Alcohol abuse, n (\%) } \\
\hline No & $85(33)$ & $54(35)$ & $31(31)$ & ns \\
\hline In the past & $23(9)$ & $15(10)$ & $8(8)$ & ns \\
\hline Yes & $147(58)$ & $85(55)$ & $62(61)$ & ns \\
\hline Missing, $\mathrm{n}$ & 55 & 21 & 34 & na \\
\hline \multicolumn{5}{|l|}{ Tumor localization, n (\%) } \\
\hline Oral cavity & $63(20)$ & $36(21)$ & $27(20)$ & ns \\
\hline Oropharynx & $149(48)$ & $77(44)$ & $72(53)$ & ns \\
\hline Hypopharynx & $44(14)$ & $33(19)$ & $11(8)$ & .008 \\
\hline Larynx & $39(13)$ & $16(9)$ & $23(17)$ & ns \\
\hline Multi-compartemental & $15(5)$ & $13(7)$ & $2(2)$ & .016 \\
\hline \multicolumn{5}{|l|}{ Tumor category, n (\%) } \\
\hline $\mathrm{T} 1$ & $25(8)$ & $9(5)$ & $16(12)$ & .036 \\
\hline $\mathrm{T} 2$ & $95(31)$ & $42(24)$ & $53(39)$ & .004 \\
\hline $\mathrm{T} 3$ & $102(33)$ & $59(34)$ & $43(32)$ & ns \\
\hline $\mathrm{T} 4$ & $88(28)$ & $65(37)$ & $23(17)$ & $<.001$ \\
\hline \multicolumn{5}{|l|}{ Nodal category, n (\%) } \\
\hline NO & $36(12)$ & $17(10)$ & $19(14)$ & ns \\
\hline N1 & $55(18)$ & $21(12)$ & $34(25)$ & .004 \\
\hline
\end{tabular}


Table 1 (continued)

\begin{tabular}{|c|c|c|c|c|}
\hline Characteristic & All patients $(n=310)$ & $\begin{array}{l}\text { pPEG } \\
(n=175)\end{array}$ & nPEG or rPEG $(n=135)$ & $P$ value \\
\hline N2 & $206(66)$ & $128(73)$ & $77(57)$ & .003 \\
\hline N3 & $11(4)$ & $9(5)$ & $5(4)$ & ns \\
\hline \multicolumn{5}{|l|}{ UICC stage (7th edition), n (\%) } \\
\hline III & $65(21)$ & $22(13)$ & $43(32)$ & $<.001$ \\
\hline IVA & $228(74)$ & $142(81)$ & $86(64)$ & $<.001$ \\
\hline IVB & $17(5)$ & $11(6)$ & $6(4)$ & ns \\
\hline \multicolumn{5}{|l|}{ Surgical interventions, n (\%) } \\
\hline Primary oncologic resection & $78(25)$ & $42(27)$ & $36(27)$ & ns \\
\hline Neck dissection & $214(69)$ & $121(69)$ & $93(69)$ & ns \\
\hline \multicolumn{5}{|l|}{ PEG tube placement, n (\%) } \\
\hline Prophylactic & $175(56)$ & $175(100)$ & $0(0)$ & na \\
\hline Reactive & $34(11)$ & $0(0)$ & $34(25)$ & na \\
\hline None & $101(33)$ & $0(0)$ & $101(75)$ & na \\
\hline Median (range) duration of PEG dependency, days & $266(4-2969)$ & $274(40-2969)$ & $231(4-2554)$ & $<.001$ \\
\hline \multicolumn{5}{|l|}{ Chemotherapy, n (\%) } \\
\hline Concomitant & $266(86)$ & $161(92)$ & $105(78)$ & $<.001$ \\
\hline Neoadjuvant & $33(11)$ & $21(12)$ & $12(9)$ & ns \\
\hline
\end{tabular}

BMI body mass index, CTCAE Common Terminology Criteria for Adverse Events, na not applicable, ns not significant, $n$ PEG no PEG, PEG percutaneous endoscopic gastrostomy, PPEG prophylactic PEG, rPEG reactive PEG, RT radiotherapy, UICC Union for International Cancer Control

Table 2 Overview of unplanned hospitalizations $(n=310)$

\begin{tabular}{llll}
\hline UH & \multicolumn{2}{l}{$\begin{array}{l}\text { No. of patients } \\
\text { (\%) }\end{array}$} & All UHs, no. of events (\%) \\
\cline { 2 - 3 } & UH1 & UH2 & \\
\hline Any UH & $141(45)$ & $64(21)$ & 205 events in 169 patients \\
Reason for UH & & & \\
Comorbidity-related & $34(11)$ & $16(5)$ & $50(24)$ \\
Alcoholism & $4(12)$ & $0(0)$ & $4(8)$ \\
Cardiopulmonary & $9(27)$ & $3(19)$ & $12(24)$ \\
Gastrointestinal & $4(12)$ & $0(0)$ & $4(8)$ \\
Infection & $12(35)$ & $5(31)$ & $17(34)$ \\
$\quad$ Other & $5(14)$ & $8(50)$ & $13(26)$ \\
Related to tumor or & $19(6)$ & $14(4)$ & $33(16)$ \\
relapse & & & \\
Treatment-related & $88(28)$ & $34(11)$ & $122(60)$ \\
(TRUH) & $11(13)$ & $1(2)$ & $12(10)$ \\
$\begin{array}{l}\text { Due to PEG } \\
\text { Due to surgery }\end{array}$ & $3(3)$ & $1(3)$ & $4(3)$ \\
Due to neoadjuvant & $4(4)$ & $2(6)$ & $6(5)$ \\
$\quad$ CX & & $29(85)$ & $99(81)$ \\
Due to radio-CX & $70(80)$ & 20
\end{tabular}

CX chemotherapy, TRUH treatment-related unplanned hospitalization, $U H$ unplanned hospitalization, UH1 first $\mathrm{UH}$ event, $U H$ second UH event

tumor localization; Table 1). In the nPEG group, apart from (chemo)-RT-related side effects, dysphagia/dehydration/malnutrition $(\mathrm{n}=8 ; 20 \%)$ was the most frequent cause of TRUH, whereas in the pPEG group, apart from
(chemo)-RT-related side effects, PEG-related complications frequently led to TRUH $(n=11 ; 14 \%)$. There was no difference in TRUH caused by PEG complications or dysphagia/malnutrition/dehydration after PPEG versus nPEG $(p=0.56)$. PEG tube placement is associated with the risk of complications; however, there is a great deal of variability in the reported incidence of such complications [11, 20, 24-29]. The difference in the incidences of complications is partly due to the various definitions and populations analyzed. For example, complications are more likely to occur in older patients with comorbidities, especially those with an infection or history of aspiration [30]. Compared with the publication of Silander et al. [10], our rate of PEG-related complications is relatively high (14\% vs $1 \%)$; however, it is relatively low compared with a prospective study reporting complication rates at 2 weeks and 2 months (39\% and 27\%, respectively) [24]. We hypothesize that our pPEG cohort is a different, more fragile patient population that tends to have more complications compared with that studied by Silander et al. [10] and our nPEG population. Furthermore, we suspect that patients-like those studied by our Swedish colleagues [10] — who are willing to be included and randomized in a study, are more compliant than the patients with HNSCC seen in our everyday practice, over two-thirds of whom have a positive history of alcohol abuse and more than $87 \%$ a positive history of tobacco use [31]. Patients with severe clinical and psychosocial impairment and fewer economic resources are more 

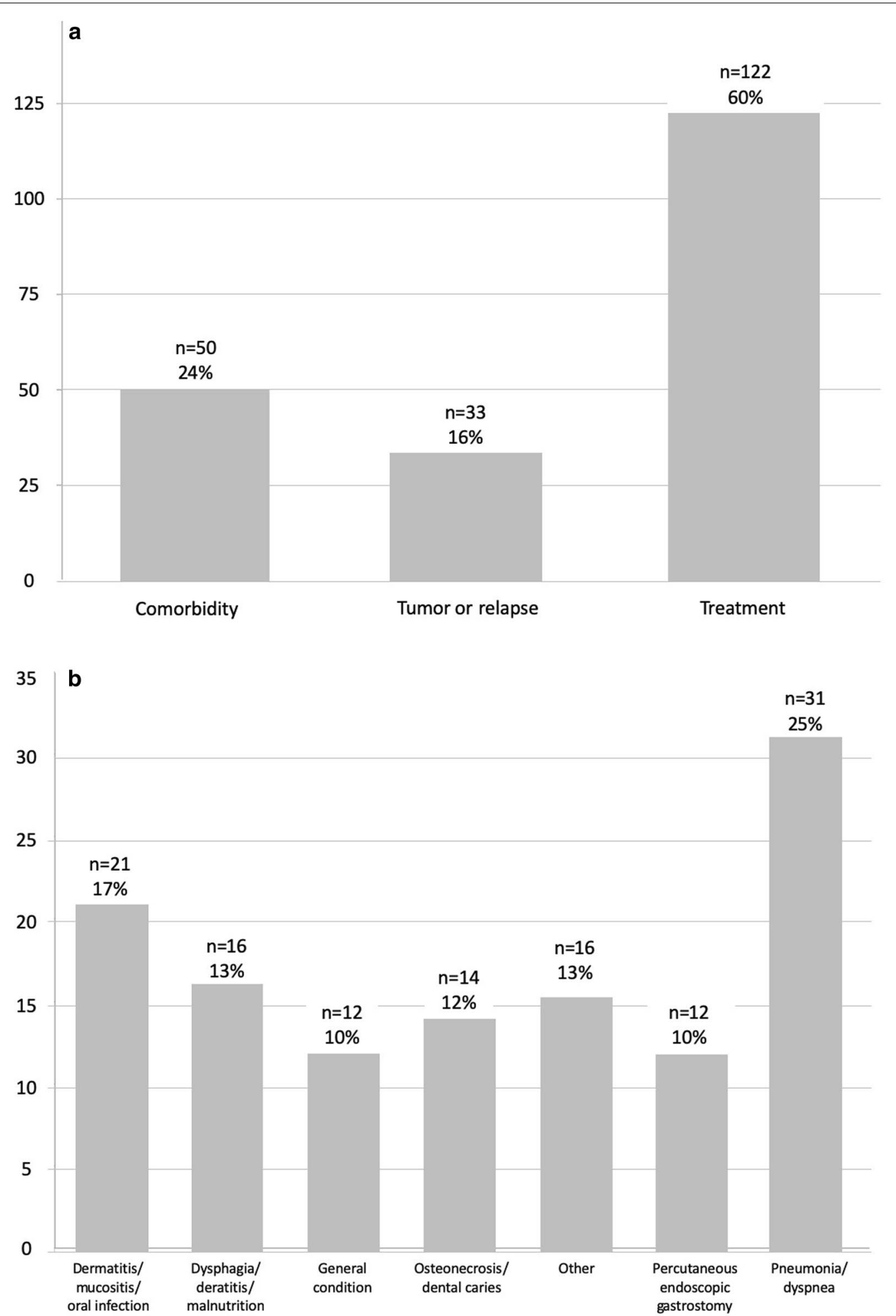

Fig. 1 Overview of a causes leading to unplanned hospitalizations (UHs) and $\mathbf{b}$ to treatment related unplanned hospitalizations (TRUHs) 
Table 3 Details of TRUHs $(n=310)$

\begin{tabular}{|c|c|c|c|c|c|c|}
\hline \multirow[t]{2}{*}{ Reason for TRUH } & \multicolumn{2}{|c|}{$\begin{array}{l}\text { All patients } \\
(\mathrm{n}=310)\end{array}$} & \multicolumn{2}{|c|}{$\begin{array}{l}\text { pPEG } \\
(n=175)\end{array}$} & \multicolumn{2}{|c|}{$\begin{array}{l}\text { nPEG or } r \text { PEG } \\
(n=135)\end{array}$} \\
\hline & No & (\%) & No & (\%) & No & (\%) \\
\hline \multicolumn{7}{|l|}{ TRUH1 $(n=88)$} \\
\hline Dermatitis/mucositis/oral infection & 18 & (20) & 13 & (23) & 5 & (16) \\
\hline Dysphagia/dehydration/malnutrition & 15 & (17) & 7 & (12) & 8 & (26) \\
\hline General condition & 8 & (9) & 5 & (9) & 3 & (10) \\
\hline Osteonecrosis/dental caries & 8 & (9) & 5 & (9) & 3 & (10) \\
\hline Other & 11 & (11) & 7 & (13) & 4 & (13) \\
\hline Percutaneous endoscopic gastrostomy & 11 & (14) & 9 & (16) & 2 & (6) \\
\hline Pneumonia/dyspnea & 17 & (19) & 11 & (19) & 6 & (19) \\
\hline Total & 88 & (28) & 57 & (33) & 31 & (23) \\
\hline \multicolumn{7}{|l|}{ TRUH2 $(n=34)$} \\
\hline Dermatitis/mucositis/oral infection & 3 & (9) & 3 & (13) & 0 & (0) \\
\hline Dysphagia/dehydration/malnutrition & 1 & (3) & 1 & (4) & 0 & (0) \\
\hline General condition & 4 & (12) & 2 & (8) & 2 & (20) \\
\hline Osteonecrosis/dental caries & 6 & (18) & 3 & (13) & 3 & (30) \\
\hline Percutaneous endoscopic gastrostomy & 3 & (9) & 0 & (0) & 1 & (10) \\
\hline Pneumonia/dyspnea & 14 & (41) & 11 & (46) & 3 & (30) \\
\hline Other & 3 & (9) & 4 & (17) & 1 & (10) \\
\hline Total & 34 & (11) & 24 & (14) & 10 & (7) \\
\hline \multicolumn{7}{|l|}{ All TRUHs $(n=122)$} \\
\hline Dermatitis/mucositis/oral infection & 21 & (17) & 16 & (20) & 5 & (12) \\
\hline Dysphagia/dehydration/malnutrition & 16 & (13) & 8 & (10) & 8 & (20) \\
\hline General condition & 12 & (10) & 7 & (9) & 5 & (12) \\
\hline Osteonecrosis/dental caries & 14 & (11) & 8 & (10) & 6 & (15) \\
\hline Percutaneous endoscopic gastrostomy & 12 & (12) & 11 & (14) & 1 & (10) \\
\hline Pneumonia/dyspnea & 31 & (25) & 22 & (27) & 9 & (22) \\
\hline Other & 13 & (11) & 9 & (11) & 4 & (10) \\
\hline Total number & 122 & $(-)$ & 81 & $(-)$ & 41 & $(-)$ \\
\hline
\end{tabular}

na not applicable, $n$ s not significant, TRUH treatment-related unplanned hospitalization, $T R U H 1$ first TRUH event, TRUH2 second TRUH event, $n P E G$ no percutaneous endoscopic gastrostomy, $P P E G$ prophylactic percutaneous endoscopic gastrostomy, $r P E G$ reactive percutaneous endoscopic gastrostomy

likely to experience treatment compliance problems [31]. There is an increasing incidence of oropharyngeal cancer, especially in younger patients, and a decrease in the previously known risk factors for HNSCC of smoking and alcohol use [32,33]. Previously, typical patients with HNSCC tended to be heavy drinkers or smokers; however, human papillomavirus (HPV)-associated HNSCC in younger, fitter, and possibly more compliant patients increasingly represent the majority of at least oropharyngeal disease [34]. This interesting aspect should be kept in mind before considering that in our entire cohort, up to one-fifth of patients had a TRUH besides the (chemo)RT-induced TRUH-due to dysphagia/dehydration/ malnutrition $(20 \%)$ in the nPEG group or postoperatively after PEG insertion (12\%) in the pPEG group. The physician and patient have to face the additional risks associated with an invasive procedure, such as PEG tube placement, or those arising from not performing a supportive surgical procedure to allow sufficient oral intake, such as dysphagia/dehydration/malnutrition.

Further differences between our cohort and the Swedish study $[10,11]$ can be seen with regard to weight loss, BMI, and OS between the pPEG and nPEG groups. The increased weight loss and BMI differences during RT in the nPEG versus pPEG groups could be explained not only by the greater compliance of patients but also by the prospective setting-and therefore thorough monitoring by nutrition counselors in the nPEG cohort-of the Silander et al. trial [10]. Nutrition counselors were not systematically involved in the treatment of our patients, and some patients categorically refused nutrition counseling. The higher risk profile in the pPEG group more easily explains the OS difference versus the nPEG group (tumor size, age, tumor localization; Table 1), as OS is known 


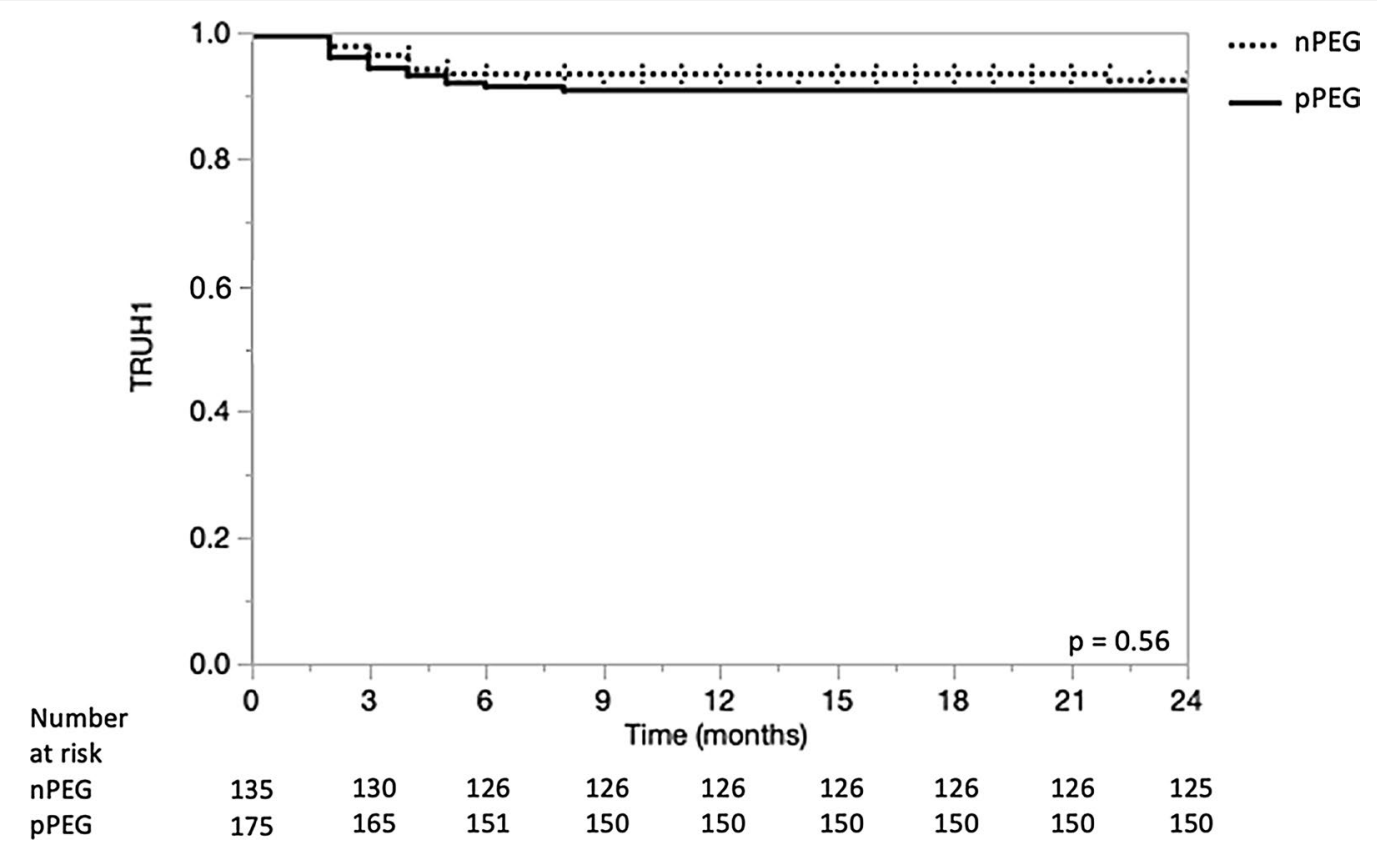

Fig. 2 Kaplan-Meier curve comparing treatment-related unplanned hospitalizations (TRUHs) caused by prophylactic PEG tube installment (pPEG) versus TRUHs caused by omitting a PEG tube (dysphagia/dehydration/malnutrition)

to be worse in patients with larger primary tumors and hypopharyngeal tumor [35-38]. Other limitations of our study, apart from the different risk profiles of the nPEG and PPEG groups, include its retrospective nature, the lack of stratification according to HPV status, and the presence of some patients treated with surgery before RT.

With future changes in the HNSCC population, therapy regimens, and side-effect profile according to the HPV status, further analyses of the indication for a PEG is necessary [39].

\section{Conclusions}

Our retrospective analysis shows that omitting a prophylactic PEG does not lead to more unplanned hospitalizations compared to patients receiving a PEG tube before start of chemoradiation. Patients with a hypopharyngeal carcinoma, active tobacco consumption, more than 40 pack-years of smoking history, and poor ECOG PS seem to be at risk of PEG tube-related UH. Prospective trials about pPEG, especially for oropharyngeal carcinoma 
Table 4 Univariate and multivariate analysis (Cox proportional-hazard)

\begin{tabular}{|c|c|c|c|c|c|c|}
\hline \multirow[t]{2}{*}{ Variable } & \multicolumn{2}{|l|}{ TRUH1 } & \multicolumn{2}{|l|}{ TRUH2 } & \multicolumn{2}{|l|}{ os } \\
\hline & HR $(95 \% \mathrm{Cl})$ & $P$ value & HR (95\% Cl) & $P$ value & HR $(95 \%$ Cl) & $P$ value \\
\hline \multicolumn{7}{|l|}{ Univariate } \\
\hline \multicolumn{7}{|l|}{ Age, years } \\
\hline$\leq 60$ & $0.76(0.48-1.18)$ & .21 & $0.74(0.35-1.56)$ & .42 & $0.63(0.42-0.96)$ & .0288 \\
\hline$>60-\leq 70$ & $1.00(0.64-1.58)$ & .99 & $1.07(0.51-2.67)$ & .86 & $0.92(0.60-1.40)$ & .6884 \\
\hline$>70-\leq 80$ & $1.43(0.82-2.50)$ & .20 & $1.59(0.65-3.91)$ & .30 & $1.40(0.84-2.34)$ & .1937 \\
\hline$>80$ & $1.52(0.61-3.75)$ & .35 & $0.80(0.11-5.85)$ & .82 & $4.25(2.26-7.99)$ & .0001 \\
\hline \multicolumn{7}{|c|}{ ECOG PS at first consultation, (vs other PS) } \\
\hline 0 & $0.95(0.60-1.51)$ & .83 & $0.89(0.41-1.91)$ & .76 & $0.64(0.41-1.00)$ & .0475 \\
\hline 1 (vs others) & $0.73(0.47-1.14)$ & .16 & $0.59(0.28-1.26)$ & .17 & $1.05(0.71-1.58)$ & .7939 \\
\hline 2/3 (vs others) & $1.99(1.15-3.45)$ & .01 & $2.77(1.23-6.27)$ & .01 & $2.01(1.21-3.37)$ & .0061 \\
\hline \multicolumn{7}{|l|}{ Alcohol abuse } \\
\hline Active & $1.16(0.71-1.88)$ & .55 & $0.81(0.36-1.83)$ & .60 & $1.23(0.78-1.94)$ & .3783 \\
\hline Active or in past & $1.59(0.92-2.75)$ & .09 & $1.17(0.48-2.85)$ & .72 & $1.33(0.82-2.16)$ & .2475 \\
\hline$>2$ units a day (= median) & $1.44(0.81-2.57)$ & .21 & $0.84(0.30-2.35)$ & .73 & $1.06(0.63-1.79)$ & .8203 \\
\hline \multicolumn{7}{|l|}{ Smoking habits } \\
\hline Current smoker & $1.13(0.70-1.82)$ & .61 & $0.94(0.41-2.13)$ & .87 & $1.06(0.68-1.66)$ & .7832 \\
\hline Current or ex-smoker & $1.68(0.74-3.92)$ & .20 & $3.39(0.46-25.1)$ & .20 & $1.14(0.59-2.21)$ & .7022 \\
\hline$>40$ pack-years (=median) & $1.94(1.17-3.20)$ & .01 & $1.98(0.81-4.85)$ & .12 & $1.01(0.63-1.63)$ & .9615 \\
\hline \multicolumn{7}{|l|}{ Tumor localization, yes (vs no) } \\
\hline Oral cavity & $1.06(0.62-1.81)$ & .83 & $0.81(0.31-2.12)$ & .67 & $0.80(0.48-1.36)$ & .409 \\
\hline Oropharynx & $0.75(0.48-1.17)$ & .19 & $0.75(0.36-1.56)$ & .43 & $0.63(0.42-0.95)$ & .026 \\
\hline Hypopharynx & $1.43(0.81-2.50)$ & .20 & $2.00(0.86-4.69)$ & .10 & $1.81(1.11-2.93)$ & .0149 \\
\hline Larynx & $1.21(0.66-2.23)$ & .53 & $0.79(0.24-2.60)$ & .69 & $1.39(0.81-2.38)$ & .2251 \\
\hline Mixed & $0.80(0.25-2.52)$ & .69 & $1.60(0.38-6.73)$ & .56 & $1.81(0.74-4.48)$ & .1878 \\
\hline \multicolumn{7}{|l|}{ Surgery, yes (vs no) } \\
\hline Primary oncologic surgery & $0.72(0.42-1.24)$ & .22 & $0.47(0.16-1.34)$ & .15 & $0.79(0.49-1.29)$ & .3395 \\
\hline Neck dissection & $0.69(0.44-1.07)$ & .09 & $0.47(0.23-0.96)$ & .03 & $0.66(0.44-0.99)$ & .0438 \\
\hline Bilateral ND & $1.69(1.08-2.64)$ & .00 & $1.75(0.84-3.67)$ & .13 & $0.92(0.58-1.45)$ & .7161 \\
\hline Tracheostomy & $1.78(1.15-2.77)$ & .01 & $2.58(1.24-5.35)$ & .01 & $1.49(0.98-2.25)$ & .0594 \\
\hline pPEG & $1.46(0.93-2.30)$ & .09 & $2.56(1.09-5.99)$ & .02 & $1.24(0.82-1.86)$ & .3003 \\
\hline rPEG & $2.54(1.48-4.33)$ & .00 & $1.75(0.67-4.58)$ & .25 & $2.07(1.25-3.43)$ & .0038 \\
\hline \multicolumn{7}{|l|}{ Chemotherapy, yes (vs no) } \\
\hline Neoadjuvant & $1.53(0.83-2.83)$ & .57 & $2.82(1.20-6.60)$ & .01 & $1.26(0.69-2.31)$ & .4535 \\
\hline Concomitant & $1.22(0.61-2.43)$ & .16 & $2.08(0.50-8.76)$ & .30 & $0.59(0.35-1.02)$ & .054 \\
\hline \multicolumn{7}{|l|}{ Baseline BMI, kg/m² } \\
\hline$\leq 18.5$ & $1.11(0.27-4.54)$ & .89 & $1.46(0.20-10.8)$ & .71 & $3.42(1.23-9.50)$ & .0115 \\
\hline$>18.5-<25$ & $0.70(0.41-1.22)$ & .20 & $0.73(0.30-1.73)$ & .46 & $0.94(0.56-1.58)$ & .8135 \\
\hline$\geq 25$ & $1.39(0.81-2.38)$ & .22 & $1.29(0.55-3.02)$ & .55 & $0.88(0.53-1.47)$ & .6231 \\
\hline \multicolumn{7}{|l|}{ Multivariate } \\
\hline \multicolumn{7}{|l|}{ Model 1 for TRUH1 } \\
\hline ECOG 2/3 & $1.73(0.93-3.23)$ & .10 & - & - & - & - \\
\hline$>40$ pack-years & $1.94(1.17-3.20)$ & .01 & - & - & - & - \\
\hline Bilateral ND & 1.69 (1.02-2.78) & .04 & - & - & - & - \\
\hline \multicolumn{7}{|l|}{ Model 2 for TRUH2 } \\
\hline ECOG 2/3 & - & - & $2.77(1.23-6.27)$ & .03 & - & - \\
\hline pPEG & - & - & $2.06(0.87-4.91)$ & .09 & - & - \\
\hline Neoadjuvant CX & - & - & $3.27(1.38-7.74)$ & .02 & - & - \\
\hline
\end{tabular}


Table 4 (continued)

\begin{tabular}{|c|c|c|c|c|c|c|}
\hline \multirow[t]{2}{*}{ Variable } & \multicolumn{2}{|l|}{ TRUH1 } & \multicolumn{2}{|l|}{ TRUH2 } & \multicolumn{2}{|l|}{ os } \\
\hline & HR $(95 \%$ Cl) & $P$ value & HR $(95 \%$ Cl) & $P$ value & HR (95\% Cl) & $P$ value \\
\hline \multicolumn{7}{|l|}{ Model 3 for OS } \\
\hline Age $>80$ years & - & - & - & - & $4.25(2.26-7.99)$ & .00 \\
\hline ECOG 2/3 & - & - & - & - & $1.64(0.94-2.85)$ & .10 \\
\hline rPEG & - & - & - & - & $1.95(1.18-3.25)$ & .02 \\
\hline
\end{tabular}

$P$ values in bold are significant at $P<0.05$

$B M I$ body mass index, $C l$ confidence interval, ECOG PS Eastern Cooperative Oncology Group performance status, $H R$ hazard ratio, OS overall survival, TRUH treatmentrelated unplanned hospitalization, TRUH1 first TRUH event, TRUH2 second TRUH event, $P P E G$ prophylactic percutaneous endoscopic gastrostomy, $r P E G$ Reactive percutaneous endoscopic gastrostomy, ND neck dissection, $C X$ chemotherapy

and its future results concerning de-escalation, are warranted.

\section{Supplementary Information}

The online version contains supplementary material available at https://doi. org/10.1186/s13014-020-01727-9.

Additional file 1. Complete multivariate analyses.

\section{Abbreviations}

PEG: Percutaneous endoscopic gastrostomy; pPEG: Prophylactic percutaneous endoscopic gastrostomy; nPEG: No prophylactic percutaneous endoscopic gastrostomy; rPEG: Reactive percutaneous endoscopic gastrostomy; UH: Unplanned hospitalization; TRUH: Treatment-related unplanned hospitalization; RT: Radiotherapy; UICC: Union for International Cancer Control; HNSCC: Head and neck squamous cell carcinoma; CTCAE: Common Terminology Criteria for Adverse Events; OS: Overall survival; BMI: Body mass index; na: Not applicable; ns: Not significant; Cl: Confidence interval; ECOG PS: Eastern Cooperative Oncology Group performance status; HR: Hazard ratio; ND: Neck dissection; CX: Chemotherapy.

\section{Authors' contributions}

Each author participated in the work and takes public responsibility for appropriate portions of the content. $\mathrm{BB}, \mathrm{OE}$, and $\mathrm{KZ}$ designed the study. $\mathrm{BB}$ and $\mathrm{OE}$ performed the statistical analysis. BB, BKS, and PL collected the data, and together with $\mathrm{OE}, \mathrm{MS}, \mathrm{AJSM}, \mathrm{BH}, \mathrm{RG}, \mathrm{DMA}$, and $\mathrm{KZ}$, interpreted the results. The manuscript was written by $\mathrm{BB}, \mathrm{BKS}, \mathrm{PL}$, and all other authors reviewed and finally approved the final manuscript. All authors read and approved the final manuscript.

\section{Funding}

No funding was received.

\section{Availability of data and materials}

The datasets used and/or analyzed during the current study are available from the corresponding author on reasonable request.

\section{Ethics approval and consent to participate}

All patients provided written consent for the use of their medical data for research purposes. Approval of the regional ethics committee (Kantonale Ethikkommission Bern - Ref.-Nr. KEK-BE: 289/2014) was obtained.

\section{Consent for publication}

All patients provided written consent for the publication of research performed with their medical data.

\section{Competing interests}

No potential conflict of interest are to declare.

\begin{abstract}
Author details
${ }^{1}$ Department of Radiation Oncology, Inselspital, Bern University Hospital, University of Bern, Bern, Switzerland. ${ }^{2}$ Department of Nuclear Medicine, Inselspital, Bern University Hospital, University of Bern, Bern, Switzerland. ${ }^{3}$ Department of Visceral Surgery and Medicine, Division of Gastroenterology, Inselspital, Bern University Hospital, University of Bern, Bern, Switzerland. ${ }^{4}$ Department of Otorhinolaryngology, Head and Neck Surgery, Inselspital, Bern University Hospital, University of Bern, Bern, Switzerland. ${ }^{5}$ Department of Radiation Oncology, Stadtspital Triemli, Birmensdorferstrasse 497, 8063 Zurich, Switzerland.
\end{abstract}

Received: 14 Auqust 2020 Accepted: 6 December 2020

Published online: 14 December 2020

References

1. Newman LA, Vieira F, Schwiezer V, et al. Eating and weight changes following chemoradiation therapy for advanced head and neck cancer. Arch Otolaryngol Head Neck Surg. 1998;124(5):589-92.

2. Rosenthal DI, Trotti A. Strategies for managing radiation-induced mucositis in head and neck cancer. Semin Radiat Oncol. 2009;19(1):29-34.

3. Peponi E, Glanzmann C, Willi B, Huber G, Studer G. Dysphagia in head and neck cancer patients following intensity modulated radiotherapy (IMRT). Radiat Oncol. 2011;6:1.

4. Sanguineti G, Gunn GB, Parker BC, Endres EJ, Zeng J, Fiorino C. Weekly dose-volume parameters of mucosa and constrictor muscles predict the use of percutaneous endoscopic gastrostomy during exclusive intensitymodulated radiotherapy for oropharyngeal cancer. Int J Radiat Oncol Biol Phys. 2011;79(1):52-9.

5. Vlacich G, Spratt DE, Diaz R, et al. Dose to the inferior pharyngeal constrictor predicts prolonged gastrostomy tube dependence with concurrent intensity-modulated radiation therapy and chemotherapy for locallyadvanced head and neck cancer. Radiother Oncol. 2014;110(3):435-40.

6. Common Terminology Criteria for Adverse Events (CTCAE) _ CTCAE_ v5_Quick_Reference_5x7.pdf. https://ctep.cancer.gov/protocoldevelop ment/electronic_applications/docs/CTCAE_v5_Quick_Reference_5x7. pdf. Accessed.

7. Nugent B, Lewis S, O'Sullivan JM. Enteral feeding methods for nutritional management in patients with head and neck cancers being treated with radiotherapy and/or chemotherapy. Cochrane Database Syst Rev. 2013;1:CD007904.

8. Madhoun MF, Blankenship MM, Blankenship DM, Krempl GA, Tierney WM. Prophylactic PEG placement in head and neck cancer: how many feeding tubes are unused (and unnecessary)? World J Gastroenterol. 2011;17(8):1004-8. 
9. Locher JL, Bonner JA, Carroll WR, et al. Prophylactic percutaneous endoscopic gastrostomy tube placement in treatment of head and neck cancer: a comprehensive review and call for evidence-based medicine. JPEN J Parenter Enter Nutr. 2011;35(3):365-74.

10. Silander E, Nyman J, Bove M, Johansson L, Larsson S, Hammerlid E. Impact of prophylactic percutaneous endoscopic gastrostomy on malnutrition and quality of life in patients with head and neck cancer: a randomized study. Head Neck. 2012;34(1):1-9.

11. Axelsson L, Silander E, Nyman J, Bove M, Johansson L, Hammerlid E. Effect of prophylactic percutaneous endoscopic gastrostomy tube on swallowing in advanced head and neck cancer: a randomized controlled study. Head Neck. 2017;39(5):908-15.

12. Geretschlager A, Bojaxhiu B, Crowe S, et al. Outcome and patterns of failure after postoperative intensity modulated radiotherapy for locally advanced or high-risk oral cavity squamous cell carcinoma. Radiat Oncol. 2012;7:175.

13. Geretschlager A, Bojaxhiu B, Dal Pra A, et al. Definitive intensity modulated radiotherapy in locally advanced hypopharygeal and laryngeal squamous cell carcinoma: mature treatment results and patterns of locoregional failure. Radiat Oncol. 2015;10:20.

14. Eisbruch A, Foote RL, O'Sullivan B, Beitler JJ, Vikram B. Intensity-modulated radiation therapy for head and neck cancer: emphasis on the selection and delineation of the targets. Semin Radiat Oncol. 2002;12(3):238-49.

15. Eisbruch A, Marsh LH, Dawson LA, et al. Recurrences near base of skull after IMRT for head-and-neck cancer: implications for target delineation in high neck and for parotid gland sparing. Int J Radiat Oncol Biol Phys. 2004;59(1):28-42.

16. Gregoire V, Levendag P, Ang KK, et al. CT-based delineation of lymph node levels and related CTVs in the node-negative neck: DAHANCA, EORTC, GORTEC, NCIC, RTOG consensus guidelines. Radiother Oncol. 2003;69(3):227-36.

17. Tehrany N, Kitz J, Rave-Frank M, et al. High-grade acute organ toxicity and p16(INK4A) expression as positive prognostic factors in primary radio(chemo)therapy for patients with head and neck squamous cell carcinoma. Strahlenther Onkol. 2015;191(7):566-72.

18. Wolff HA, Daldrup B, Jung K, et al. High-grade acute organ toxicity as positive prognostic factor in adjuvant radiation and chemotherapy for locally advanced head and neck cancer. Radiology. 2011;258(3):864-71.

19. Ponsky JL, Gauderer MW, Stellato TA. Percutaneous endoscopic gastrostomy. Review of 150 cases. Arch Surg. 1983;118(8):913-4.

20. Burney RE, Bryner BS. Safety and long-term outcomes of percutaneous endoscopic gastrostomy in patients with head and neck cancer. Surg Endosc. 2015;29(12):3685-9.

21. Kramer S, Newcomb M, Hessler J, Siddiqui F. Prophylactic versus reactive PEG tube placement in head and neck cancer. Otolaryngol Head Neck Surg. 2014;150(3):407-12.

22. Orphanidou C, Biggs K, Johnston ME, et al. Prophylactic feeding tubes for patients with locally advanced head-and-neck cancer undergoing combined chemotherapy and radiotherapy-systematic review and recommendations for clinical practice. Curr Oncol. 2011;18(4):e191-201.

23. Romesser PB, Romanyshyn JC, Schupak KD, et al. Percutaneous endoscopic gastrostomy in oropharyngeal cancer patients treated with intensity-modulated radiotherapy with concurrent chemotherapy. Cancer. 2012;118(24):6072-8.

24. Blomberg J, Lagergren J, Martin L, Mattsson F, Lagergren P. Complications after percutaneous endoscopic gastrostomy in a prospective study. Scand J Gastroenterol. 2012;47(6):737-42.
25. Keung EZ, Liu X, Nuzhad A, Rabinowits G, Patel V. In-hospital and longterm outcomes after percutaneous endoscopic gastrostomy in patients with malignancy. J Am Coll Surg. 2012;215(6):777-86.

26. Larson DE, Burton DD, Schroeder KW, DiMagno EP. Percutaneous endoscopic gastrostomy. Indications, success, complications, and mortality in 314 consecutive patients. Gastroenterology. 1987;93(1):48-52.

27. Park SK, Kim JY, Koh SJ, et al. Complications of percutaneous endoscopic and radiologic gastrostomy tube insertion: a KASID (Korean Association for the Study of Intestinal Diseases) study. Surg Endosc. 2019;33(3):750-6.

28. Schneider AS, Schettler A, Markowski A, et al. Complication and mortality rate after percutaneous endoscopic gastrostomy are low and indicationdependent. Scand J Gastroenterol. 2014;49(7):891-8.

29. Taylor CA, Larson DE, Ballard DJ, et al. Predictors of outcome after percutaneous endoscopic gastrostomy: a community-based study. Mayo Clin Proc. 1992;67(11):1042-9.

30. Raha SK, Woodhouse K. The use of percutaneous endoscopic gastrostomy (PEG) in 161 consecutive elderly patients. Age Ageing. 1994;23(2):162-3.

31. Herbeck DM, Fitek DJ, Svikis DS, Montoya ID, Marcus SC, West JC. Treatment compliance in patients with comorbid psychiatric and substance use disorders. Am J Addict. 2005;14(3):195-207.

32. Hafkamp HC, Speel EJ, Haesevoets A, et al. A subset of head and neck squamous cell carcinomas exhibits integration of HPV 16/18 DNA and overexpression of p16INK4A and p53 in the absence of mutations in p53 exons 5-8. Int J Cancer. 2003;107(3):394-400.

33. Pai SI, Westra WH. Molecular pathology of head and neck cancer: implications for diagnosis, prognosis, and treatment. Annu Rev Pathol. 2009;4:49-70.

34. Chaturvedi AK, Engels EA, Pfeiffer RM, et al. Human papillomavirus and rising oropharyngeal cancer incidence in the United States. J Clin Oncol. 2011;29(32):4294-301.

35. Bonner JA, Harari PM, Giralt J, et al. Radiotherapy plus cetuximab for squamous-cell carcinoma of the head and neck. N Engl J Med. 2006;354(6):567-78.

36. Chao KS, Low DA, Perez CA, Purdy JA. Intensity-modulated radiation therapy in head and neck cancers: the Mallinckrodt experience. Int J Cancer. 2000;90(2):92-103.

37. Lee N, Xia P, Fischbein NJ, Akazawa P, Akazawa C, Quivey JM. Intensitymodulated radiation therapy for head-and-neck cancer: the UCSF experience focusing on target volume delineation. Int J Radiat Oncol Biol Phys. 2003;57(1):49-60.

38. Mendenhall WM, Amdur RJ, Palta JR. Intensity-modulated radiotherapy in the standard management of head and neck cancer: promises and pitfalls. J Clin Oncol. 2006;24(17):2618-23.

39. Mehanna H, Robinson M, Hartley A, et al. Radiotherapy plus cisplatin or cetuximab in low-risk human papillomavirus-positive oropharyngeal cancer (De-ESCALaTE HPV): an open-label randomised controlled phase 3 trial. Lancet. 2019;393(10166):51-60.

\section{Publisher's Note}

Springer Nature remains neutral with regard to jurisdictional claims in published maps and institutional affiliations.

\footnotetext{
Ready to submit your research? Choose BMC and benefit from:

- fast, convenient online submission

- thorough peer review by experienced researchers in your field

- rapid publication on acceptance

- support for research data, including large and complex data types

- gold Open Access which fosters wider collaboration and increased citations

- maximum visibility for your research: over 100M website views per year
}

At BMC, research is always in progress.

Learn more biomedcentral.com/submissions 